\title{
Quality assessment of mixed plastic flakes from Waste Electrical and Electronic Equipment (WEEE) by spectroscopic techniques
}

Florian Wagner ${ }^{12}$, Jef R. Peeters ${ }^{1}$, Hans Ramon ${ }^{1}$, Jozefien De Keyzer ${ }^{2}$, Joost R. Duflou ${ }^{1}$, Wim Dewulf ${ }^{1}$

${ }^{1}$ KU Leuven - University of Leuven, Department of Mechanical Engineering, Leuven, Belgium ${ }^{2} K U$ Leuven - University of Leuven, Department of Chemical Engineering, Diepenbeek, Belgium

\begin{abstract}
The quality of mechanically recycled plastics from WEEE is seen as one of the main bottlenecks for their re-application in high-quality products to enable a circular economy for these materials. Most literature focuses on the quality at the end of the value chain while significant potential to improve the performance of the entire value chain is seen by the quality assessment of input material of recyclers. In this research a testing procedure for mixed plastic flakes by Fourier-Transform InfraRed (FTIR) spectroscopy, X-Ray Fluorescence (XRF) and manual composition analysis assisted by computer vision. Mixed plastics from TV housings, washing machines, fridges and fridge drawers were taken as case studies. It is shown that unwanted plastic types, glass, metals, wood, rubber and foam as well as additives such as talc, calcium carbonate or brominated flame retardants can be detected by the procedure. In addition, a Failure Mode and Effect Analysis (FMEA) is shown to be a powerful tool for a risk-based assessment of the most relevant quality influences, which allows to define strategies for quality control. The economic evaluation showed that automation is required to allow the systematic use of the testing procedure.
\end{abstract}




\section{Introduction}

Plastics recycling has a significant potential to reduce the emission of $\mathrm{CO}_{2}$ to the atmosphere and save on natural resources by replacing virgin plastics. Today, it is estimated that recycled plastics make only up to $1 \mathrm{wt} \%$ of new electronic and electrical equipment (Lhotellier, 2017). One of the bottlenecks is the mistrust of the manufacturers in the availability of recycled plastics with a high and consistent quality (European Commission, 2018)Recyclers have the objective to meet the quality requirements of manufacturers, which is challenging due to a long chain of different processes and actors in the plastics recycling value chain. WEEE is collected and subsequently treated in pre-processing facilities for decontamination, material concentration and the creation of materials streams (Chancerel et al., 2009). Size-reduction techniques are used to liberate the different materials. From the resulting mixed pieces, metals are commonly removed before the mixed plastic flakes reach the plastics sorting processes, such as sink-float separation, electrostatic separation or spectroscopic separation (Buekens and Yang, 2014; Cui and Forssberg, 2003; Ragaert et al., 2017; Uepping, 2013; F. Wagner et al., 2018). Resulting streams of single plastic types are molten in compounding to add addititves, improve material properties or to include a melt filtration step to remove solid impurities (Lacoste et al., 1996; Markarian, 2008; Xu et al., 2005).

\section{Quality of recycled plastics}

Quality needs are mostly defined by the manufacturers or regulating bodies and translated into material requirements to ease the search for suitable materials (F. S. Wagner et al., 2018). However, relevant quality aspects that will be relevant for most applications of recycled plastics from WEEE are considered to be mechanical properties, rheological properties, aesthetics and legal compliance, which are mainly influenced by impurities, additives, contaminants and irreversible chemical ageing (Eriksen et al., 2018; Vilaplana and Karlsson, 2008; Wagner et al., 2019).

\section{$\underline{\text { Impurities }}$}

The purity of a polymer is seen as the main influence on the quality of a recycled plastic (Eriksen et al., 2018; Perrin et al., 2016). Already relatively small amounts of foreign bodies in the polymer matrix can have severe effect on mechanical, rheological or aesthetical properties. Kühnel et al. (Kühnel et al., 2019) showed that concentrations as low as $0.17 \mathrm{wt} \%$ of paper labels in PolyCarbonate/Acrylonirtile Butadiene Styrene (PC/ABS) can result in a loss of $96 \%$ in strain at break, while comparable concentrations of PolyPropylene (PP) labels resulted in a significantly lower influence. Not only the type of impurity but also the size, shape and distribution in the polymer matrix will determine the final effect the impurity has on the quality of the recycled plastic (Adams, 1993; Eriksson et al., 1998; Perrin et al., 2016). Eriksen and Astrup (Eriksen and Astrup, 2019) concluded that products designed for recycling can significantly increase the quality of the recycled plastics originating from these products. In addition, the copolymer composition of PC/ABS, ratio of PC and ABS, has been shown to strongly influences the mechanical performance (Nigam et al., 2005). While the copolymer composition it is precisely defined for virgin plastics, the ratio in recycled plastics will depend on the input mix of different PC/ABS grades. 


\section{$\underline{\text { Additives }}$}

The use of additives such as talc, calcium carbonate, gypsum or wollastonite fillers will influence the stiffness, thermal stability, shrinkage and impact strength (Jiang et al., 2005; Kuram, 2019; Putra et al., 2009). A rise in viscosity can be expected for filled polymers, as reported for the addition of $\mathrm{CaCO} 3$ to polypropylene (Lazzeri et al., 2005). Also glass fibres influence the viscosity, depending on fibre concentration, length and orientation (Crowson and Folkes, 1980; Eberle et al., 2008). Uncontrolled fluctuations in the concentrations of fillers can lead to property fluctuations and glass fibres can cause wear of the tools and processing equipment (Lazzeri et al., 2005). In the context of WEEE plastics, different types of Flame Retardants (FRs), mostly based on phosphorous and Brominated (Br), are commonly used and can influence the mechanical properties.

\section{Contaminants}

More importantly, some types of Br FR can be seen as contaminants as they are subject to legislative restrictions (European Commission, 2012). Their presence causes a severe risk for compliance to RoHS and REACH, which requires a systematic removal of all plastic flakes containing Br FRs (EERA, 2018). The type and amount of FRs in WEEE depends on the product as well as on the plastic types (Hennebert and Filella, 2018; Jandric et al., 2019). In addition to restricted Br FR types, also other substances that threaten legislative compliance or have unwanted negative effects on the quality can be defined as contaminants. They are mostly low molecular organic substances, but also consist of metals such lead, cadmium or mercury, that are subject to restrictions by the RoHS directive (RoHS recast Directive 2011/65/EU, 2011). Also additives such as phthalate plasticizers or colour formulations including cadmium risk compliance issues for recycling (RoHS recast Directive 2011/65/EU, 2011).

\section{Irreversible chemical ageing}

Ageing is often caused by the exposure to moisture, oxygen, temperature or electromagnetic irradiation and high share rates and high temperatures during processing and cause changes in mechanical and aesthetical properties as well as dimensional stability (Agroui and Collins, 2015; Bociąga and Trzaskalska, 2016; Facio et al., 2015; Miranda et al., 2001; Yousif and Haddad, 2013). Physical ageing processes, such as changes in crystallinity, relaxation processes or inner tensions are reversed when the polymer is molten (Ehrenstein and Pongratz, 2013; Guo et al., 2019; Strangl et al., 2019). Chemical changes on the other hand are mostly irreversible. Examples are changes in molecular mass, crosslinking, decomposition reactions, the formation of functional groups or the formation of low molecular products (Ehrenstein and Pongratz, 2013). Consequences can be a decrease of the impact strength due to crosslinking of the butadiene phase of ABS, HIPS and PC/ABS, a reduction in strain at break due to chain scission or the formation of oxygen containing chemical groups (Bai et al., 2007; Boldizar and Möller, 2003; Tarantili et al., 2010; Vilaplana et al., 2010). Also degradation products can form, such as different volatile oligomers due to the decomposition of polystyrene (Marczewski et al., 2013) or the decay of highly Brominated Diphenyl Ethers (BDEs) into brominated congeners (Mas et al., 2008). 
The main goal of this research is to improve the quality management for plastic recycling in order to increase the availability of post-consumer recycled plastics with a high and consistent quality. Most literature focuses on the quality of recycled plastic at the end of the value chain, while early stages are poorly investigated (Beigbeder et al., 2013; Perrin et al., 2016; Vilaplana and Karlsson, 2008). Significant potential to improve the performance of the entire value chain is seen in the quality assessment of mixed plastic flakes that serve as input in plastic sorting facilities. This stage is often subject to trade with pre-processors and mixed flakes mostly still contain metals, glass or other impurities. For this purpose a testing procedure based on FTIR, $\mathrm{XRF}$, manual composition analysis and Computer Vision (CV) is proposed. The technical capabilities of the techniques to detect relevant quality influences are presented based on selected case studies and a literature review. A risk assessment based on a Failure Mode and Effect Analysis (FMEA) evaluates the control of the most important quality requirements for plastic flakes. Further, an economic evaluation investigates the systematic application of the procedure and shows the potentials of automation of this procedure.

\section{Materials and Methods}

\subsection{Materials}

Three categories of WEEE were selected as sources of plastics for the four case studies used in the presented research: TV housings, washing machines, fridges and fridge drawers. The knowledge on TV housings is based on previous research, including a sampling trial at a recycler in Belgium in 2016 of approximately 8 tonnes of LCD TV back covers and a composition analysis (Vanegas et al., 2017; F. Wagner et al., 2018). The plastic flakes of fridges were collected during a sampling trial at a pre-processing plant in Italy in 2019. In another sampling trial, 1.5 tonne of fridge drawers were manually removed from fridges during the depollution step. In total $500 \mathrm{~kg}$ of every colour: transparent, white and smoky were separately collected. The flakes from washing machines were collected in a sampling trial of 20 tonnes in Italy in 2019. For the detection of talc and calcium carbonate in PP by FTIR, virgin PP HE125MO from Borealis was mixed with 0, 2, 4, 8, 17, 25, 34, $42 \mathrm{wt} \%$ calcium carbonate masterbatch ISOFIL H $40 \mathrm{C} 2 \mathrm{~F}$ NA and 0, 4, 7, 14, 29, 43, 58, $72 \mathrm{wt} \%$ of talc masterbatch (unknown supplier) in a laboratory mixer at increased temperatures.

\subsection{Methods}

The investigated testing technique for plastic flakes is composed of FTIR spectroscopy, XRF and Manual Composition Analysis (MCA) assisted by Computer Vision (CV). Sieving at 3 $\mathrm{mm}$ is included to determine the amount of fines (Fig 1).

The manual composition analysis is conducted on the entire sample of approximately $5 \mathrm{~kg}$ and serves to determine the sample composition by weight. In addition, the manual composition analysis can include an estimation by eye to give a rough estimate on the colour composition of the mixed plastic flakes. However, such indications do not allow to calculate the potential yield or final colour of the recyclate. Therefore, a computer vision system developed by Ramon et al. (Ramon et al., 2018) is used to determine the colour distribution in a more precise, reliable 
and fast manner for mixed plastic flakes. This technique also determines the flake size and distribution of the flakes. The sample is representatively split in two and one half is used for the computer vision analysis. The used setup consists of a line camera and a controlled light source on a conveyor belt, which is an improved version of the setup as described by Ramon et al. (Ramon et al., 2018).

The other half was shredded to $5 \mathrm{~mm}$ flakes and well mixed for analysis by FTIR to determination the plastic composition and additives, which is a common technique for the identification of unknown plastics and commonly available at recycling facilities. Signoret et al. (Signoret et al., 2019) showed that most relevant WEEE plastics can be discriminated with this technique. Some plastics are relatively difficult do discriminate and require a very good quality of the measured spectra. For the FTIR measurements a Thermo Fisher Nicolet iS5 was used, which was included in an automated setup that used plastic pieces of approximately 5 $\mathrm{mm}$ as an input material, compresses the pieces to small sample plates and positions them on the ATR crystal of the FTIR. Approximately 70-100 spectra of high-quality comparable to spectra measured by hand were used to determine the plastic composition.

$\mathrm{XRF}$ can be used to measure the bromine content in the plastics, which helps to control the risk of restricted $\mathrm{Br}$ additives by applying RoHS restriction levels of $1000 \mathrm{ppm}$ as a threshold (directive 2011/65/EU). XRF is a fast screening method with measurement times of a few seconds for lab scale devices and has been reported to allow to control bromine levels of 300 ppm (Aldrian et al., 2015). Discussion with sales representatives revealed that for specific plastic types detection levels of 6 - 8 ppm have been realized, but not proven in the context of plastics recycling. However, the technique does not allow to distinguish restricted from nonrestricted Br FRs, which would require dedicated chemical analysis. In addition to bromine, XRF allows to check the presence of lead, mercury and chromium to give indications for compliance to RoHS (Mans et al., 2007). Other techniques to measure bromine in plastic flakes at higher detection levels are Sliding Spark SPectroscopy (SSSP), Laser Induced Breakdown Spectrometry (LIBS) and Fourier Transform InfraRed spectroscopy (FTIR). All techniques and relevant detection levels form bromine in plastics are shown in Table 1. XRF measurements were conducted on 20 flakes for the fridge, fridge drawers and washing machine case studies by a third-party laboratory. The chemical analysis of 20 flakes per sample for REACH compliance was conducted by a third-party testing institute by XRF, Gas Chromatography (GC), High Pressure Liquid Chromatography (HPLC) and Inductively Coupled Plasma (ICP) combined with Mass Spectrometry (MS).

\subsection{Failure mode and effect analysis}

The Failure Mode and Effect Analysis (FMEA) is a risk evaluation tool that helps to identify potential quality failures in systems or products (Hu et al., 2009; Liu et al., 2013). To prioritize possible failure modes the Probability of a failure $(\mathrm{P})$, the Severity of the failure (S) and the likelihood of detecting the failure (D) are multiplied to obtain the Risk Priority Number (RPN). The RPN is defined on a scale of 1 to 1000 and allows to rank risks and determine a focus of measures for risk reduction. In this paper the method is adapted to the risk assessment of quality influences for recycled plastics in order to improve the quality management of these materials. 
The FMEA is used as a method to evaluate the quality control of the proposed testing procedure of mixed plastic flakes.

\section{Definition of the influences on quality for mixed plastic flakes}

The quality concepts from Vilaplana et al. (Vilaplana and Karlsson, 2008) and previous research on a quality assessment of WEEE on product level (Florian Wagner et al., 2019) were used to determine the quality influences on recycled plastics as shown in Fig 2.

The basic structure for quality influences is provided in the categories purity and degree of degradation. The purity describes the presence of impurities on macro level and additives and contaminants on micro level. The presence of impurities is sub-categorized into plastics (other than the targeted plastic), glass/concrete/ceramic, metals, wood/paper, rubber, foam. These main categories of impurities were defined together with recyclers and based on experience achieved from plastic recycling projects. For the investigated case studies, the relevant additives are talc, calcium carbonate, glass fibres, phosphorous retardants and colourants. The relevant contaminants are brominated flame retardants and restricted substances (according to RoHS and REACH). The degree of degradation is defined by the irreversible chemical changes, which are predominantly defined by crosslinking, chain scission and oxidation.

The definition of quality influences is strongly connected to the case studies (sources of WEEE plastics) and targeted quality. As a general approach it is recommended to consider the waste category (e.g. WEEE), the waste products (e.g. fridges) and the plastic (e.g. polystyrene) in order to define the quality influences. For the definition of additives Hahladakis et all provided a good overview of different additives that are used in plastics (Hahladakis et al., 2018). Contaminants can be defined by applicable legislation based on the source and targeted quality: REACH regulation (1907/2006/EC), POP regulation (2019/1021/EU), RoHS for electronic and electrical applications (directive 2011/65/EU), for toys (directive 2009/48/EC) or food contact applications (directive EC/282/2008). Furthermore, company specific requirements or other substances that cause quality issues, such as low molecular compounds that produce smell can be included.

Probability of presence $(\mathrm{P})$. In this research TV housings, washing machines, fridges, fridge drawers were investigated WEEE sources for recycled plastics. The probability of presence of effects that influence the quality is defined on a scale from 1 to 10,1 meaning it is very unlikely and 10 meaning the presence is very likely (Table 2). The estimation of presence is based on the composition analysis results of the case study products, knowledge from previous analysis and discussion with OEMs and knowledge on the requirements for plastics used in their products. Possible sorting errors are also taken into account, so that e.g. the presence of glass in plastics from fridges is very likely, due to the common use of glass trays in fridges. The probabilities for all case study products are estimated in a similar manner for all case studies.

Probability of non-detection (D). The detection expresses the capability of a testing technique to identify one of the defined quality influences, 1 meaning that it is almost sure that a quality influence is detected by the technique and 10 that it is almost impossible. For the analysis in this research the capability was estimated based on testing, previous research and a literature study. The testing techniques included in this research are standard techniques that can be found 
in material testing labs of plastic recyclers. An exception are the chemical analysis techniques GC, HPLC and ICP combined with MS, which are analysis that are typically outsourced by recycling companies. The detection capability is considered at the level of mixed plastic flakes (input material) at the stage before the plastic sorting and compounding and is not to be confused with the detection limit.

Severity for the quality (S). The severity for the quality estimates the effect the different influences might have on the final quality on product level. In this paper the quality is expressed in four categories, the mechanical properties, the rheological properties, the aesthetical properties and legal compliance. While in this research the four categories are not ranked, also weighing by precentral multiplication is possible to define one severity for the quality.

\subsection{Economic evaluation of the flake testing procedure}

An economic evaluation of the proposed flake testing procedure is done to analyse the economic viability and investigate the potential for the development of a fully automated setup. The cost for utilities and chemicals and the labour cost are included in the operating cost. For the Differential Scanning Calorimetry (DSC), Gas Chromatography (GC) + Mass Spectrometry (MS), High Pressure Liquid Chromatography (HPLC) + MS and Inductive Coupled Plasma (ICP) + MS a labour costs of $110 € / \mathrm{h}$ is estimated for skilled staff and for all other testing techniques $50 € / \mathrm{h}$ is assumed. Labour time includes sample preparation, the effectively needed time to conduct the measurement and the time required for the analysis of the results. The total time it takes an operator to prepare a sample for the automated system is estimated to be 45 minutes for one batch. This time is equally distributed to the automated FTIR, XRF and CV in the operating cost calculation. The costs of the purchase of the testing techniques are calculated for labscale equipment. The amount of measurements per year for every technique are based on the specific measurement time for every technique and the amount of measurements suggested per batch of mixed flakes. To calculate the costs per measurement, 3 years of use of the equipment as well as 300 operational days of 8 hours are assumed. The equipment cost of the automated setup with FTIR, XRF and CV analysis, 100 $000 €$ are estimated based on $65000 €$ for the measurement equipment and $35000 €$ for the automated sample preparation and software. The total costs per measurement were calculated by the addition of the operating and investment costs per measurement. The amount of input material in from of plastic flakes was estimated an discussions with industrial partners to be 45 000 tonnes of input material.

\section{Result and discussion}

\subsection{Technical evaluation of the testing procedure for plastic flakes}

\section{$\underline{\text { Impurities }}$}

For the detection of the impurities the Manual Composition Analysis (MCA) allows to identify the relative share of plastics, glass, metals, wood, rubber and foam. The results of the composition analysis in Table 3 show that the removal of the fridge drawers before size reduction resulted in a pure plastic fraction of 100 and 99 wt \%, while the sample of entire 
fridges contained $97.5 \mathrm{wt} \%$ plastics. The mixed fraction from fridges was subject to a flotation process to remove metals and enrich the plastics. Regardless, $0.4 \mathrm{wt} \%$ of metals are still found in the plastics, which should have been removed during the plastic separation step. A previous sampling trial in 2018 without flotation showed a high metal content of $9.7 \mathrm{wt} \%$, a low plastic content of $80.9 \mathrm{wt} \%$ and a very high fines content of $8.5 \mathrm{wt} \%$. While it is assumed that during the plastic separation and compounding process most impurities and the fines content will be removed, the results of the MCA indicate a significantly different performance of the three fridge samples.

The plastic composition of the samples was analysed by FTIR spectroscopy and showed that the mixed plastic flakes of fridges contained a high content of $47.4 \mathrm{wt} \%$ HIPS, $16.7 \mathrm{wt} \%$ PS, $23 \mathrm{wt} \%$ ABS and $2.5 \mathrm{wt} \% \mathrm{PP}, 1.3 \mathrm{wt} \% \mathrm{PE}$ and $3.8 \mathrm{wt} \% \mathrm{PC} / \mathrm{ABS}$, which are plastic types that are today commercially recycled. HIPS and PS are compatible and it can be considered to the recycle the two polymers together, considering that the impact strength will be influenced. The discrimination of HIPS from PS is possible by FTIR, but the accuracy is limited. PS and HIPS are chemically different due to the butadiene rubber phase in the HIPS, which gives a relatively weak response in FTIR (Lacoste et al., 1996). In addition, overlaps of peaks and the presence of unknown additives in the polymer further complicate the analysis. The discrimination of ABS from HIPS is done based on the acrylonitrile group, which gives a response around 2236 $\mathrm{cm}^{-1}$ in FTIR. Due to frequent background noises in this region, the discrimination requires a very good quality of the FTIR spectra. The $0.1 \mathrm{wt} \%$ of PVC comes from cables and can cause problems for the quality of the plastics as well as damage to the compounding and injection moulding tools. The samples of fridges without flotation showed a significantly higher content of PVC with $3 \mathrm{wt} \%$. Comparing the samples from fridges to the samples of separately treated fridge drawers, a significant change in the plastic composition is observed. Depending on the colour, the transparent fridge drawers are dominated by $89.3 \mathrm{wt} \%$ PS and the white fridge drawers by $64.5 \mathrm{wt} \%$ HIPS. While this shows that the selected treatment of the removed drawers allows to enrich specific polymer types, another advantage is that the drawers are produced by very high-quality food contact approved plastics, which is not required for all plastic components in fridges and could bring added value to the recycled plastics from this stream.

The main gain of the flake analysis by MCA and FTIR is to calculate the expected yield of targeted plastics in the composition. Furthermore, processing mistakes from pre-processors that lead to a high fines-content or the unexpected increase of relative shares of materials can be identified and allow to define subsequent processing decisions for plastic sorting. The results show that an analysis already at early stages in the supply chain can evaluate the performance of pre-processing. The FTIR analysis of plastic flakes has the advantage that also relatively low concentrations of potential impurities can be measured, given that a large amount of flakes are measured. Once the plastics have been compounded only high concentrations of plastics in other plastics can be identified. On example is the identification of PP in ABS which is possible for concentrations of $10 \mathrm{wt} \% \mathrm{PP}$ (Camacho and Karlsson, 2001). 


\section{$\underline{\text { Additives }}$}

The controlled mixing of talc and $\mathrm{CaCO}_{3}$ with virgin PP and subsequent measurement by FTIR was conducted to identify the presence these fillers by the proposed flake testing system. Fig 3 displays representative FTIR spectra for unfilled, $32 \mathrm{wt} \%$ talc filled and $34 \mathrm{wt} \% \mathrm{CaCO} 3$ filled PP. It can be seen that pure PP is characterized by peaks at 2952, 2916, 2865, 3837, 1455, 1374 $\mathrm{cm}^{-1}$ (Socrates, 2001). The peak at $2952 \mathrm{~cm}^{-1}$ was used as a reference peak to investigate absorbance changes in the spectra after the addition of $0,4,7,14,29,43,58,72 \mathrm{wt} \%$ talc and $0,2,4,8,17,25,34,42 \mathrm{wt} \%$ CaCO3 (Fig 4).

For talc filler mainly peaks at 3673, 1005 and $667 \mathrm{~cm}^{-1}$ occurred and increased with higher concentrations. The increase in the peak at $874 \mathrm{~cm}^{-1}$ is caused by the shoulder of the $1005 \mathrm{~cm}^{-}$ ${ }^{1}$ peak. For the $\mathrm{CaCO}_{3}$ filler new peaks form at $1420,874,714 \mathrm{~cm}^{-1}$, which can be confirmed by literature (Al-Hosney and Grassian, 2005). Based on the results it is estimated that the presence of talc and $\mathrm{CaCO}_{3}$ can be clearly identified in recycled plastics by FTIR for concentrations of minimum 10-15 wt $\%$. In contrasts, single tests on $40 \mathrm{wt} \%$ glass fibre filled PP did not yield visible peaks in FTIR. Experiments on selected plastic flakes showed that most glass fibre, talc or calcium carbonate containing PP flakes can be removed from the unfilled flakes by a density separation in water at $1 \mathrm{~g} / \mathrm{cm} 3$. Heavy PP flakes that appear unfilled in FTIR can then be classified as glass fibre filled samples. However, low concentrations of fillers were still observed in the light fraction. Regardless, the integration of a density separations step before analysis by FTIR, XRF and manual composition analysis is seen as a useful step that can be applied depending on the source and the associated risk of their presence.

While TV housings are like most WEEE defined by black and grey colours (Peeters et al., 2014), the washing machines, fridges and fridge drawers contain a significant share of white, light grey and transparent colours. They are considered more valuable, as they can be mixed with new colourants to achieve green, blue or other colours. Almost all plastics contain colourants to define the aesthetical appearance. Fig 5 shows that the mixed flakes of washing machines contain fewer white colours and that washing machines are dominated by light grey shades. The amount of green flakes in the fridge flakes is based on a relatively large share of small flakes, which are subject to measurement mistakes of the used conveyor belt.

\section{Contaminants}

RoHS and REACH tests of 20 flakes per mixture showed no compliance concerns for fridge drawers, while washing machine samples indicated the presence of boron, phthalates and cadmium at elevated levels for single flakes. While the affected flakes might still be removed during the recycling process and concentrations of the mixture are expected to be under the legal limit, the results already indicate that risk of contamination is associated with different sources. Previous research showed that the TV housings from HIPS contained high concentrations of brominated flame retardants, including the restricted deca-BDE (F. Wagner et al., 2019a).

Testing the bromine content already at an early stage by XRF can give more detailed insight in the origin of bromine, if the source information is provided. A systematic monitoring can help to better control the bromine levels of recycled plastics. In addition, the share of plastic flakes 
containing bromine can influence price evaluations between pre-processors and recyclers, as bromine containing plastics need to be incinerated (Weber and Kuch, 2003), resulting in a cost for the recycler.

\section{$\underline{\text { Irreversible chemical changes }}$}

The presence of $\mathrm{C}-\mathrm{O}, \mathrm{C}=\mathrm{O}$ and $\mathrm{O}-\mathrm{H}$ groups were measured in polystyrene flakes from fridges in the wave number ranges $1710-1750,1050-1100 \mathrm{~cm}^{-1}$ and $4000-3000 \mathrm{~cm}^{-1}$, respectively (Li et al., 2017; Socrates, 2001). Discussion with manufacturers revealed that the oxidation of HIPS is caused by the surface treatment with a Corona process that produces oxidative groups to form a polar surface needed for the gluing of foam. As this form of treatment only affects the surface and does not cause chain scission or a decrease in the rubber phase inside the polymer, no significant quality decrease is expected. However, the use of stabilizers can be considered to avoid possible influences on the degradation by the increased amount of oxygen groups in the polymer. While FTIR is a sensitive tool for the detection of oxidative groups, for the analysis of flakes in recycling only severe cases of oxidation of a polymer surface can be identified, due to the lack of reference spectra of the non-oxidized polymer surface, which is usually used for analysis. The presence of the $\mathrm{O}-\mathrm{H}$ group is also likely to be the result of moisture in the polymer surface. In addition, the $\mathrm{C}-\mathrm{O}, \mathrm{C}=\mathrm{O}$ groups can be present in additives and fro some types of plastics are part of the polymer chain.

The detection of chain scission and crosslinking is not feasible with FTIR. Additional measurements by MFI or DSC can indicate a high/low viscosity and high/low rubber phase, respectively. However, also these techniques cannot determine whether this is the result of chemical ageing, due to the lack of reference values

\subsection{Failure mode and effect analysis for plastic flakes testing}

The FMEA was used to analyse three scenarios: no testing, proposed testing procedure with FTIR, XRF and MCA (or CV), all techniques (Fig 6).

\section{$\underline{\text { Impurities }}$}

The probability of presence of most impurities is similar for the TV housings, washing machines and fridges. While the amount of impurities might vary, they are all very likely to contain the impurities and as already small amounts can cause severe defects in the mechanical properties and aesthetics, the risk assessment resulted in comparable probability values. A significant difference can be observed for the case of separated fridge drawers, as the isolation of this plastic stream before size reduction allows to reduce the risk of impurities significantly. While the MCA and FTIR composition results do not directly reflect the probability of presence in the FMEA, it is expected that systematic testing in connection with source and processing information can contribute to gradually improve the risk estimations. No differences in the RPN are observed for the testing procedure by FTIR, XRF, manual composition analysis and computer vision and the scenario of all testing techniques. Therefore, no risk differences compared to the measurement by all techniques is observed. 


\section{$\underline{\text { Additives }}$}

The use of glass fibres is only common for producing the plastic drum housings for washing machines, while the use in the other investigated sources is highly unlikely. The procedure is shown to perform well in the detection of talc and calcium carbonate and also the risk of undetected colourants is significantly reduced. As the presence of glass fibres was identified as the largest remaining risk in the FMEA, a possible analysis based on density was investigated. The presence of phosphorous FRs can be expected mainly for the TV housings (Peeters et al., 2014; F. Wagner et al., 2019b) and relevant concentrations of FRs can influence the mechanical properties such tensile modulus or strain at break (Jung et al., 1998). No detection based on the proposed testing system is possible with relevant accuracy and only indications might be derived from FTIR spectra, if the FRs are present in high concentrations. For plastic recycling the mixture of different colours can result in unwanted colour shades. This results in a higher risk of colourants for the predominantly white and light grey sources of fridges, fridge drawers and washing machines compared to TV housings.

\section{Contaminants}

In the FMEA it is visible that the highest risk of the presence of Br FRs is in TV housings. However, the presence in washing machines or fridges cannot be ruled out. Only the presence in fridge drawers that need to be food contact approved plastics is seen as almost impossible. The removal of the fridge drawers and subsequent separate treatment allows to isolate a highquality source that might require only little substance control. While legal compliance needs to be proven at the end of the value chain at product level, the analysis of mixed plastic flakes can already give a good indication of possible threats for RoHS compliance by XRF. The source of the plastic as well as the plastic type can already give some indication on possible substances and help to identify high-risk sources. This stresses the importance of connecting systematic or semi-regular testing to source and processing information.

\section{$\underline{\text { Irreversible chemical changes }}$}

As TV housings are often exposed to sunlight, they are estimated to have a higher risk to oxidation compared to fridge drawers that are exposed to low temperatures an no ultraviolet light. Oxidation can result in a loss in mechanical performance, but also aesthetical properties are expected to be influenced by discolouration. Chain scission is expected to occur for all plastics regardless of the source due to high temperatures and shear rates during processing. The risk of irreversible chemical changes is one of the main limitations of the proposed testing procedure. Due to shredding and processing some degree of degradation is expected in all plastics, while the possibilities to detect the degradations for plastic flakes are limited. The most promising strategy to control the chain scission and crosslinking is by rheological testing and impact testing at granulate level and improvement in compounding by the addition of chain extends and impact modifiers.

The FMEA is seen as a powerful tool to visualize quality related risks for recycled plastics and to define strategies to control them. The systematic testing of input material by the proposed testing procedure can contribute significantly to detect and control some of the most important quality influences. While most limitations, such as the determination of low molecular 
compounds that could threaten legal compliance, the presence of glass fibres as well as chemical ageing effects, could be overcome be the application of additional testing techniques. The combination of testing with metadata on the source of the mixed plastics and processing information can be used to identify high-risk sources. Consequently, dedicated treatment strategies by isolation or targeted combination of WEEE sources can be defined to control risks.

\subsection{Economic evaluation of the flake testing procedure}

The total cost per measurement for all techniques are dominated by the cost of the manual labour as shown in Table 4. The amount of measurements per batch are minimum values required to obtain relevant analysis results. In total the testing by all techniques is evaluated as a reference for the best practice testing procedure and would result in a cost of $1272 €$ per 10 tonnes of input material, is considered to be reasonable for a systematic quality assessment. This equals approximately 4.2 tonnes of output recycled plastic due to material losses and sorting. Hence, the analysis cost would account to $302 €$ per tonne, which is considered not economically viable given that the final sales price of post-consumer recycled HIPS and ABS is assumed to be 800 and $1200 €$ per tonne, respectively. Especially GC, HPLC and ICP with MS are labour intensive, often require the extraction of the substances from the polymer and skilled staff. Based on the resulting high price, the use of these techniques for compliance testing at flake level on a regular basis is not seen as economically viable. While the detection of non-compliant material at early stages can avoid processing costs, it is expected that the amount of measurements required does not outweigh the testing costs for representative sample sizes. However, the semi-regular testing of compliance by GC, HPLS and ICP with MS at early stages on a limited number of flakes can provide deeper insight in contaminants that would otherwise be diluted underneath the threshold. Thus the testing of restricted substances for high-risk batches or for the development of new recycled plastics can be a suitable option to define improved input clustering strategies for substance control. One of the main problems in plastics recycling is the that only very limited information on restricted or concerning substances in waste streams is available (Römph and Calster, 2018). As carrying out tests is very expensive, the availability of substance data from OEMs can help recyclers to identify high-risk sources. This allows to define clusters, testing procedures and dismantling strategies to better control substance levels. An example is the decontamination by the removal of CRT TV housings with a high content of Br FRs (UNEP, 2017).

The evaluation of the proposed testing procedure by FTIR, XRF and MCA (including sieving). As most recyclers will have this testing techniques in form of handheld or table top versions and manual use by the quality testing department is assumed. The procedure would cost $322 €$ per 10 tonnes of input material or $77 €$ per tonne of produced recycled plastic. Therefore, it is expected that the costs of this testing procedure cannot be carried for regular and systematic testing of input material without further reduction in cost. However, it is seen as valuable to apply it for material from new or unreliable suppliers and for research projects to determine the material composition of specific waste streams. 
The complementary use of computer vision in an automated system is expected to result in addition $14 €$ per batch and allows to analyse the colour and size distribution of the flakes. An example for the size distribution curves by computer vision of mixed plastic flakes from fridges and fridge drawers can be seen in Fig 7. The results can be used to determine material losses for yield calculations when combined with the MCA and FTIR results. Assuming a recycler uses a $5 \mathrm{~mm}$ sieving step in the process, the mixed flakes from fridges would contain $8.5 \mathrm{wt} \%$ of plastics that are smaller. Based on the target fraction of HIPS and PS of $64.1 \mathrm{wt} \%$ from the FTIR composition, only $55.6 \mathrm{wt} \%$ could be theoretically recycled. For the fridge drawers with a HIPS and PS fraction of $81.8 \mathrm{wt} \%$ and losses of only $0.6 \mathrm{wt} \%$, the theoretical yield would be $81.2 \mathrm{wt} \%$. In addition, the smaller sizes of the yield fraction of the fridges compared to the fridge drawers can results in throughput inefficiencies due to unsuitable size distributions for the subsequent separation processes. Thus, providing a size distribution of the mixed flakes can be used to detect value chain inefficiencies and can serve for improved pricing models based on yield calculations, which is expected to result in a direct benefit for the plastic recyclers and pre-processors.

To allow the proposed testing procedure by FTIR, XRF and MCA (and CV) to be systematically used for the quality assessment of input material of plastic recyclers, automation of the testing procedure is required to reduce the labour cost. Based on the experiences with the automated FTIR and CV setup used for this research, it is expected that labour time can be reduced to $45 \mathrm{~min}$ per batch of 10 tonnes compared to 345 minutes of labour time that are required for the manual testing. Further development of the automation setup is expected to reduce the 1 measurement can be reduced to 20 seconds for the FTIR and XRF measurements and less than 1 second for the computer vision. For the case that the MCA can be fully replaced the cost could be reduced to $45 €$ per 10 tonnes of input material or $11 €$ per tonne of recycled plastic (Table 5).

\section{Conclusions}

Methods for the analysis of the quality of plastic flakes along the entire value chain is not well documented in literature. Especially the stage between pre-processors and recyclers is often subject to trade. Therefore, the presented research demonstrated the . quality testing by FTIR spectroscopy, XRF and manual composition analysis, possibly assisted by computer vision allows to analyse the material composition of the mixed plastics flakes, including relevant impurities such as metals, glass, wood and other materials. In addition, it is demonstrated that these methods can be used to assess the presence of additives such as talc and calcium fillers as well as bromine, cadmium, lead, mercury that risk non-compliance according to RoHS. The main limitations are seen both in the analysis of glass fibres, which requires the addition of a density separation step and in the characterization of irreversible chemical ageing processes.

Quality assessment of mixed plastic flakes at the stage between pre-processors and recyclers increases the transparency of the value chain. In addition, the material composition combined with size and colour distribution of the plastic flakes allows recyclers to estimate the yield of their process. This can serve as a basis for yield-oriented pricing models and cross-actor optimization which is considered to encompass substantial potential for improving the 
recycling efficiency of the entire value chain. In addition, it allows to detect unexpected processing errors and anomalies that result in low processing yields and efficiencies. The economic analysis of the testing costs showed that automation is required to reduce the labour costs from 322 to $45 €$ per tonne, which is considered an acceptable testing cost for the systematic application of the testing procedure.

FMEA is known to be a powerful tool for the risk assessment and with the presented research the value of this method is also demonstrated for risk assessment related to plastic recycling. Major risks can be identified using FMEA based on the requested output quality and on prior knowledge on the origin of the material, which allows to adapt the testing procedure. The presented results highlight that the availability of information on the origin of the plastic flakes and processing history can help to identify high-risk sources. Therefore, it is believed that future research should develop methods to stimulate the exchange of such meta data. Further, significant potential is expected from the implementation of innovative clustering strategies for an improved removal of hazardous substances and to reduce the complexity of input material streams to increase the yield and quality of the recycled plastic with the state-of-theart recycling process

Future research will focus on the improved detection of impurities, such as metals, glass, wood, foam and rubber by computer vision techniques to further reduce the manual labour required for testing and hence the cost of testing.

\section{Acknowledgement}

The research for this paper is part of the PolyCE project, funded by the European Union Horizon 2020 programme. The researchers gratefully acknowledge the contribution of all partners in the PolyCE project. The authors are especially grateful to Tecnalia for producing samples, Ecodom for conduction the sampling trials, Whirlpool for analysing the fillers and UL for conducting the RoHS and REACH substance testing.

\section{References}

A. Haarman, M.G., 2016. Managing hazardous additives in WEEE plastic from the Indian informal sector.

Adams, J.M., 1993. Particle Size and Shape Effects In Material Science: Examples from Polymer and Paper Systems. Clay Minerals 28, 509-530.

Agroui, K., Collins, G., 2015. Outdoor Exposure Degradation of Ethylene-Vinyl-Acetate Encapsulant Material for Photovoltaic Application, in: Visakh, P.M., Arao, Y. (Eds.), Thermal Degradation of Polymer Blends, Composites and Nanocomposites, Engineering Materials. Springer International Publishing, pp. 193-219. https://doi.org/10.1007/978-3-319-03464-5_8

Aldrian, A., Ledersteger, A., Pomberger, R., 2015. Monitoring of WEEE plastics in regards to brominated flame retardants using handheld XRF. Waste Management 36, 297-304. https://doi.org/10.1016/j.wasman.2014.10.025 
Al-Hosney, H.A., Grassian, V.H., 2005. Water, sulfur dioxide and nitric acid adsorption on calcium carbonate: A transmission and ATR-FTIR study. Phys. Chem. Chem. Phys. 7, 1266-1276. https://doi.org/10.1039/B417872F

Bai, X., Isaac, D.H., Smith, K., 2007. Reprocessing acrylonitrile-butadiene-styrene plastics: Structure-property relationships. Polymer Engineering and Science 47, 120-130. https://doi.org/10.1002/pen.20681

Beigbeder, J., Perrin, D., Mascaro, J.-F., Lopez-Cuesta, J.-M., 2013. Study of the physicochemical properties of recycled polymers from waste electrical and electronic equipment (WEEE) sorted by high resolution near infrared devices. Resources, Conservation and Recycling 78, 105-114. https://doi.org/10.1016/j.resconrec.2013.07.006

Bociąga, E., Trzaskalska, M., 2016. Influence of ageing on the gloss, color, and structure of colored ABS. Color Res. Appl. 41, 392-398. https://doi.org/10.1002/col.21971

Boldizar, A., Möller, K., 2003. Degradation of ABS during repeated processing and accelerated ageing. Polymer Degradation and Stability 81, 359-366. https://doi.org/10.1016/S0141-3910(03)00107-1

Buekens, A., Yang, J., 2014. Recycling of WEEE plastics: a review. J Mater Cycles Waste Manag 16, 415-434. https://doi.org/10.1007/s10163-014-0241-2

Camacho, W., Karlsson, S., 2001. NIR, DSC, and FTIR as quantitative methods for compositional analysis of blends of polymers obtained from recycled mixed plastic waste. Polym Eng Sci 41, 1626-1635. https://doi.org/10.1002/pen.10860

Chancerel, P., Meskers, C.E.M., Hagelüken, C., Rotter, V.S., 2009. Assessment of Precious Metal Flows During Preprocessing of Waste Electrical and Electronic Equipment. Journal of Industrial Ecology 13, 791-810. https://doi.org/10.1111/j.15309290.2009.00171.x

Crowson, R.J., Folkes, M.J., 1980. Rheology of short glass fiber-reinforced thermoplastics and its application to injection molding. II. The effect of material parameters. Polymer Engineering \& Science 20, 934-940. https://doi.org/10.1002/pen.760201404

Cui, J., Forssberg, E., 2003. Mechanical recycling of waste electric and electronic equipment: a review. Journal of Hazardous Materials 99, 243-263. https://doi.org/10.1016/S03043894(03)00061-X

Eberle, A.P.R., Baird, D.G., Wapperom, P., 2008. Rheology of Non-Newtonian Fluids Containing Glass Fibers: A Review of Experimental Literature. Ind. Eng. Chem. Res. 47, 3470-3488. https://doi.org/10.1021/ie070800j

EERA, 2018. Responsible recycling of WEEE containing BFR's.

Ehrenstein, G.W., Pongratz, S., 2013. Resistance and Stability of Polymers. Hanser, Munich.

Eriksen, M.K., Astrup, T.F., 2019. Characterisation of source-separated, rigid plastic waste and evaluation of recycling initiatives: Effects of product design and source-separation system. Waste Management 87, 161-172. https://doi.org/10.1016/j.wasman.2019.02.006

Eriksen, M.K., Pivnenko, K., Olsson, M.E., Astrup, T.F., 2018. Contamination in plastic recycling: Influence of metals on the quality of reprocessed plastic. Waste Management 79, 595-606. https://doi.org/10.1016/j.wasman.2018.08.007 
Eriksson, P.-A., Albertsson, A.-C., Boydell, P., Månson, J. -a. E., 1998. Influence of impurities on mechanical properties of recycled glass fiber reinforced polyamide 66. Polym Eng Sci 38, 749-756. https://doi.org/10.1002/pen.10240

European Commission, 2018. A European Strategy for Plastics in a Circular Economy.

European Commission, 2012. Directive 2012/19/EU on waste electrical and electronic equipment (WEEE).

Facio, A.C., Galindo, A.S., Cepeda, L.F., López, L.L., León-Gómez, R.D. de, 2015. Thermal Degradation of Synthetic Rubber Nanocomposites, in: Visakh, P.M., Arao, Y. (Eds.), Thermal Degradation of Polymer Blends, Composites and Nanocomposites, Engineering Materials. Springer International Publishing, pp. 157-191. https://doi.org/10.1007/978-3-319-03464-5_7

Guo, H., Zheng, X., Ru, S., Luo, X., Mai, B., 2019. The leaching of additive-derived flame retardants (FRs) from plastics in avian digestive fluids: The significant risk of highly lipophilic FRs. Journal of Environmental Sciences, SI: Recent advances in Environmental Sciences 85, 200-207. https://doi.org/10.1016/j.jes.2019.06.013

Hahladakis, J.N., Velis, C.A., Weber, R., Iacovidou, E., Purnell, P., 2018. An overview of chemical additives present in plastics: Migration, release, fate and environmental impact during their use, disposal and recycling. Journal of Hazardous Materials 344, 179-199. https://doi.org/10.1016/j.jhazmat.2017.10.014

Hennebert, P., Filella, M., 2018. WEEE plastic sorting for bromine essential to enforce EU regulation. Waste Management 390-399. https://doi.org/10.1016/j.wasman.2017.09.031

Hu, A.H., Hsu, C.-W., Kuo, T.-C., Wu, W.-C., 2009. Risk evaluation of green components to hazardous substance using FMEA and FAHP. Expert Systems with Applications 36, 7142-7147. https://doi.org/10.1016/j.eswa.2008.08.031

Jandric, A., Part, F., Fink, N., Cocco, V., Mouillard, F., Huber-Humer, M., Salhofer, S., Zafiu, C., 2019. Investigation of the heterogeneity of bromine in plastic components as an indicator for brominated flame retardants in waste electrical and electronic equipment with regard to recyclability. Journal of Hazardous Materials 121899. https://doi.org/10.1016/j.jhazmat.2019.121899

Jiang, L., Lam, Y.C., Tam, K.C., Chua, T.H., Sim, G.W., Ang, L.S., 2005. Strengthening acrylonitrile-butadiene-styrene (ABS) with nano-sized and micron-sized calcium carbonate. Polymer 46, 243-252. https://doi.org/10.1016/j.polymer.2004.11.001

Jung, H.C., Kim, W.N., Lee, C.R., Suh, K.S., Kim, S.-R., 1998. Properties of Flame-Retarding Blends of Polycarbonate and Poly(Acrylonitrile-butadiene-Styrene). Journal of Polymer Engineering 18, 115-130. https://doi.org/10.1515/polyeng-1998-1-210

Kühnel, T., Wagner, F., Berthold, A., Langer, B., Keyzer, J.D., 2019. Influence of Label Impurities in Recycling on the Mechanical Properties of PC/ABS Materials. Macromolecular Symposia 384, 1900037. https://doi.org/10.1002/masy.201900037

Kuram, E., 2019. Hybridization effect of talc/glass fiber as a filler in polycarbonate/acrylonitrile-butadiene-styrene composites. Composites Part B: Engineering 173, 106954. https://doi.org/10.1016/j.compositesb.2019.106954

Lacoste, J., Delor, F., Pilichowski, J.F., Singh, R.P., Prasad, A.V., Sivaram, S., 1996. Polybutadiene content and microstructure in high impact polystyrene. Journal of 
Applied Polymer Science 59, 953-959. https://doi.org/10.1002/(SICI)10974628(19960207)59:6<953::AID-APP7>3.0.CO;2-O

Lazzeri, A., Zebarjad, S.M., Pracella, M., Cavalier, K., Rosa, R., 2005. Filler toughening of plastics. Part 1 - The effect of surface interactions on physico-mechanical properties and rheological behaviour of ultrafine CaCO3/HDPE nanocomposites. Polymer 46, 827-844. https://doi.org/10.1016/j.polymer.2004.11.111

Lhotellier, J., 2017. Material efficiency by marking in EU Ecodesign. Final report 207.

Li, J., Chen, F., Yang, L., Jiang, L., Dan, Y., 2017. FTIR analysis on aging characteristics of ABS/PC blend under UV-irradiation in air. Spectrochimica Acta Part A: Molecular and Biomolecular Spectroscopy 184, 361-367. https://doi.org/10.1016/j.saa.2017.04.075

Liu, H.-C., Liu, L., Liu, N., 2013. Risk evaluation approaches in failure mode and effects analysis: A literature review. Expert Systems with Applications 40, 828-838. https://doi.org/10.1016/j.eswa.2012.08.010

Mans, C., Hanning, S., Simons, C., Wegner, A., Janßen, A., Kreyenschmidt, M., 2007. Development of suitable plastic standards for X-ray fluorescence analysis. Spectrochimica Acta Part B: Atomic Spectroscopy 62, 116-122. https://doi.org/10.1016/j.sab.2007.02.001

Marczewski, M., Kamińska, E., Marczewska, H., Godek, M., Rokicki, G., Sokołowski, J., 2013. Catalytic decomposition of polystyrene. The role of acid and basic active centers. Applied Catalysis B: Environmental 129, 236-246. https://doi.org/10.1016/j.apcatb.2012.09.027

Markarian, J., 2008. Choosing a melt filtration system. Plastics, Additives and Compounding 10, 32-35. https://doi.org/10.1016/S1464-391X(08)70093-X

Mas, S., de Juan, A., Lacorte, S., Tauler, R., 2008. Photodegradation study of decabromodiphenyl ether by UV spectrophotometry and a hybrid hard- and softmodelling approach. Analytica Chimica Acta 618, 18-28. https://doi.org/10.1016/j.aca.2008.04.044

Miranda, T.M.R., Gonçalves, A.R., Amorim, M.T.P., 2001. Ultraviolet-induced crosslinking of poly(vinyl alcohol) evaluated by principal component analysis of FTIR spectra. Polym. Int. 50, 1068-1072. https://doi.org/10.1002/pi.745

Nigam, I., Nigam, D., Mathur, G.N., 2005. Effect of Rubber Content of ABS on Properties of PC/ABS Blends. I. Rheological, Mechanical, and Thermal Properties. Polymer-Plastics Technology and Engineering 44, 815-832. https://doi.org/10.1081/PTE-200060828

Peeters, J.R., Vanegas, P., Tange, L., Van Houwelingen, J., Duflou, J.R., 2014. Closed loop recycling of plastics containing Flame Retardants. Resources, Conservation and Recycling 84, 35-43. https://doi.org/10.1016/j.resconrec.2013.12.006

Perrin, D., Mantaux, O., Ienny, P., Léger, R., Dumon, M., Lopez-Cuesta, J.-M., 2016. Influence of impurities on the performances of HIPS recycled from Waste Electric and Electronic Equipment (WEEE). Waste Management 56, 438-445. https://doi.org/10.1016/j.wasman.2016.07.014

Putra, H.D., Ngothai, Y., Ozbakkaloglu, T., Seracino, R., 2009. Mineral filler reinforcement for commingled recycled-plastic materials. Journal of Applied Polymer Science 112, 3470-3481. https://doi.org/10.1002/app.29861 
Ragaert, K., Delva, L., Van Geem, K., 2017. Mechanical and chemical recycling of solid plastic waste. Waste Management 69, 24-58. https://doi.org/10.1016/j.wasman.2017.07.044

Ramon, H., Peeters, J.R., Beerten, C., Antico, L., Duflou, J.R., Dewulf, W., 2018. Evaluating the size an colour distribution of mixed plastic recyclates using computer vision. Presented at the Going Green CARE INNOVATION, Vienna.

RoHS recast Directive 2011/65/EU, 2011. RoHS recast Directive 2011/65/EU [WWW Document]. URL http://eur-lex.europa.eu/legal-content/EN/TXT/?uri=CE LEX:32011L0065

Römph, T.J. de, Calster, G.V., 2018. REACH in a circular economy: The obstacles for plastics recyclers and regulators. Review of European, Comparative \& International Environmental Law 27, 267-277. https://doi.org/10.1111/reel.12265

Signoret, C., Caro-Bretelle, A.-S., Lopez-Cuesta, J.-M., Ienny, P., Perrin, D., 2019. MIR spectral characterization of plastic to enable discrimination in an industrial recycling context: I. Specific case of styrenic polymers. Waste Management 95, 513-525. https://doi.org/10.1016/j.wasman.2019.05.050

Socrates, G., 2001. Infrared and Raman Characteristic Group Frequencies, 3rd ed. John Wiley \& Sons, Chichester.

Strangl, M., Ortner, E., Buettner, A., 2019. Evaluation of the efficiency of odor removal from recycled HDPE using a modified recycling process. Resources, Conservation and Recycling 146, 89-97. https://doi.org/10.1016/j.resconrec.2019.03.009

Tarantili, P.A., Mitsakaki, A.N., Petoussi, M.A., 2010. Processing and properties of engineering plastics recycled from waste electrical and electronic equipment (WEEE). Polymer Degradation and Stability, Special Issue: MoDeSt 2008 95, 405-410. https://doi.org/10.1016/j.polymdegradstab.2009.11.029

Uepping, R., 2013. Sensorgestützte Sortiertechnik, in: Recycling und Rohstoffe. ThoméKozmiensky Verlag GmbH, p. 711.

UNEP, 2017. Guidance on best available techniques and best environmental practices for the recycling and waste disposal of articles containing polybrominated diphenyl ethers (PBDEs) listed under the Stockholm Convention [WWW Document]. URL http://chm.pops.int/Implementation/NIPs/Guidance/GuidanceonBATBEPfortherecycli ngofPBDEs/tabid/3172/Default.aspx (accessed 11.26.19).

Vanegas, P., Peeters, J.R., Cattrysse, D., Dewulf, W., Duflou, J.R., 2017. Improvement potential of today's WEEE recycling performance: The case of LCD TVs in Belgium. Front. Environ. Sci. Eng. 11, 13. https://doi.org/10.1007/s11783-017-1000-0

Vilaplana, F., Karlsson, S., 2008. Quality Concepts for the Improved Use of Recycled Polymeric Materials: A Review. Macromol. Mater. Eng. 293, 274-297. https://doi.org/10.1002/mame.200700393

Vilaplana, F., Ribes-Greus, A., Karlsson, S., 2010. Chromatographic pattern in recycled highimpact polystyrene (HIPS) - Occurrence of low molecular weight compounds during the life cycle. Polymer Degradation and Stability 95, 172-186. https://doi.org/10.1016/j.polymdegradstab.2009.11.033

Wagner, Florian, Peeters, J., De Keyzer, J., Duflou, J., Dewulf, W., 2019. Quality Assessment of Plastic Recyclates from Waste Electrical and Electronic Equipment (WEEE): A Case Study for Desktop Computers, Laptops, and Tablets, in: Hu, A.H., Matsumoto, M., 
Kuo, T.C., Smith, S. (Eds.), Technologies and Eco-Innovation towards Sustainability II: Eco Design Assessment and Management. Springer, Singapore, pp. 139-154. https://doi.org/10.1007/978-981-13-1196-3_12

Wagner, F., Peeters, J., Keyzer, J.D., Duflou, J., Dewulf, W., 2018. Evaluation of the quality of postconsumer plastics obtained from disassembly-based recycling strategies. Polymer Engineering \& Science 58, 485-492. https://doi.org/10.1002/pen.24731

Wagner, F., Peeters, J.R., De Keyzer, J., Janssens, K., Duflou, J.R., Dewulf, W., 2019a. Towards a more circular economy for WEEE plastics - Part B: Assessment of the technical feasibility of recycling strategies. Waste Management 96, 206-214. https://doi.org/10.1016/j.wasman.2019.07.035

Wagner, F., Peeters, J.R., De Keyzer, J., Janssens, K., Duflou, J.R., Dewulf, W., 2019b. Towards a more circular economy for WEEE plastics - Part A: Development of innovative recycling strategies. Waste Management 100, 269-277. https://doi.org/10.1016/j.wasman.2019.09.026

Wagner, F.S., Peeters, J.R., De Keyzer, J., Duflou, J.R., Dewulf, W., 2018. Recycling of plastics from Waste Electrical and Electronic Equipment - defining minimum requirements for the reapplication in injection moulded products. Presented at the Going Green CARE INNOVATION, Vienna.

Weber, R., Kuch, B., 2003. Relevance of BFRs and thermal conditions on the formation pathways of brominated and brominated-chlorinated dibenzodioxins and dibenzofurans. Environ Int 29, 699-710. https://doi.org/10.1016/S01604120(03)00118-1

Xu, X.F., Wang, R., Tan, Z.Y., Yang, H.D., Zhang, M.Y., Zhang, H.X., 2005. Effects of polybutadiene-g-SAN impact modifiers on the morphology and mechanical behaviors of ABS blends. European Polymer Journal 41, 1919-1926. https://doi.org/10.1016/j.eurpolymj.2005.02.025

Yousif, E., Haddad, R., 2013. Photodegradation and photostabilization of polymers, especially polystyrene: review. Springerplus 2. https://doi.org/10.1186/2193-1801-2-398 
Table 1. Handheld analysis techniques and their detection levels for bromine.

\begin{tabular}{ll}
\hline Technique & Bromine Detection Level \\
\hline X-Ray Fluorescence (XRF) & $300 \mathrm{ppm}$ (Aldrian et al., 2015) \\
& $10-100 \mathrm{ppm}$ (UNEP, 2017) \\
Laser Induced Breakdown Spectroscopy (LIBS) & $1500 \mathrm{ppm}$ (A. Haarman, 2016) \\
Sliding Spark Spectroscopy (SSSP) & $1000 \mathrm{ppm}$ (UNEP, 2017) \\
Fourier Transform InfraRed spectroscopy (FTIR) & $5000 \mathrm{ppm}$ (UNEP, 2017) \\
\hline
\end{tabular}


Table 2. Scale definition of the probability, detection and severity factors.

\begin{tabular}{llll}
\hline Scale & Probability of presence & Probability of non-detection & Severity on quality \\
\hline 1 & Presence almost impossible & Almost sure & Almost None \\
2 & Presence very unlikely & Very high & Very low \\
3 & Presence unlikely & High & Low \\
4 & Presence possible, but unlikely & Moderately high & Moderately low \\
5 & Presence possible & Moderate & Moderate \\
6 & Presence possible & Moderate & Moderate \\
7 & Presence possible and likely & Moderately remote & Moderately high \\
8 & Presence likely & Remote & High \\
9 & Presence very likely & Very remote & Very high \\
10 & Presence almost sure & Almost impossible & Hazardous \\
\hline
\end{tabular}


Table 3. Material composition by manual composition analysis and FTIR

spectroscopy.

\begin{tabular}{|c|c|c|c|c|}
\hline $\begin{array}{l}\text { Material } \\
\text { composition } \\
{[\mathrm{wt} \%]}\end{array}$ & 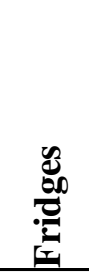 & 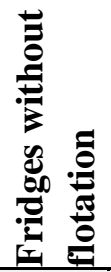 & 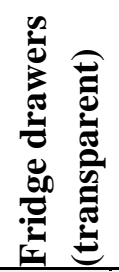 & 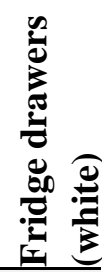 \\
\hline$\overline{\text { Plastics }}$ & 97.5 & 80.9 & 100.0 & 99.0 \\
\hline HIPS & 47.4 & 41.1 & 1.1 & 64.5 \\
\hline$P S$ & 16.7 & 20.6 & 89.3 & 17.3 \\
\hline$A B S$ & 23.0 & 11.8 & & \\
\hline SAN & & & 5.1 & \\
\hline PP unfilled & 2.5 & & & \\
\hline $\mathrm{PPCaCO}$ & 2.5 & 1.5 & & 8.1 \\
\hline PP talc & & & & 8.1 \\
\hline$P E$ & 1.3 & & & \\
\hline$P V C$ & 0.1 & 3.0 & & \\
\hline$P C$ & & & 4.5 & \\
\hline$P C / A B S$ & 3.8 & & & \\
\hline Other Plastics & & 3.0 & & 1.2 \\
\hline Metals & 0.4 & 9.7 & 0.0 & 0.0 \\
\hline Rubber & 0.1 & 0.0 & 0.0 & 0.0 \\
\hline Glass & 0.1 & 0.6 & 0.0 & 0.0 \\
\hline Wood, Paper & 0.1 & 0.1 & 0.0 & 0.0 \\
\hline Foam & 0.0 & 0.0 & 0.0 & $<0.1$ \\
\hline Other & 0.0 & 0.1 & 0.0 & 0.7 \\
\hline Fines $<3 \mathrm{~mm}$ & 1.9 & 8.5 & 0.0 & 0.3 \\
\hline
\end{tabular}


Table 4. Economic evaluation flake testing techniques

\begin{tabular}{|c|c|c|c|c|c|c|c|c|}
\hline & 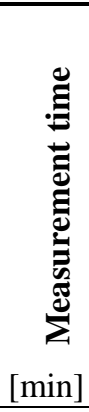 & 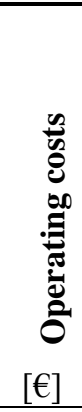 & 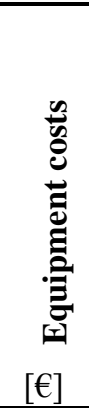 & 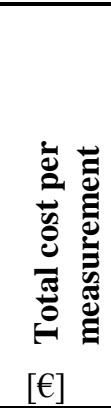 & 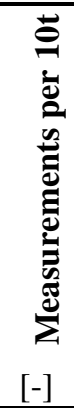 & 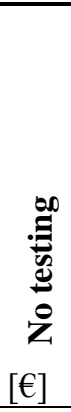 & 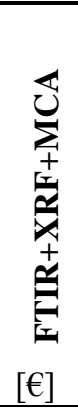 & 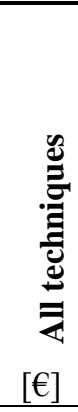 \\
\hline FTIR & 2 & 1.7 & 0.13 & 1.8 & 100 & 0 & 179 & 179 \\
\hline XRF & 2 & 1.7 & 0.17 & 1.8 & 50 & 0 & 92 & 92 \\
\hline MCA & 45 & 50.0 & 0.37 & 50.4 & 1 & 0 & 50 & 50 \\
\hline TGA & 20 & 8.8 & 2.78 & 11.6 & 3 & 0 & 0 & 35 \\
\hline DSC & 60 & 29.5 & 7.22 & 36.7 & 5 & 0 & 0 & 184 \\
\hline Density m. & 5 & 4.2 & 0.03 & 4.3 & 5 & 0 & 0 & 21 \\
\hline MFI & 30 & 25.3 & 0.78 & 26 & 1 & 0 & 0 & 26 \\
\hline Colour m. & 2 & 1.7 & 0.04 & 1.7 & 100 & 0 & 0 & 170 \\
\hline $\mathrm{GC}+\mathrm{MS}$ & 20 & 125 & 5 & 130 & 1 & 0 & 0 & 130 \\
\hline HPLC + MS & 20 & 125 & 11.1 & 136 & 1 & 0 & 0 & 136 \\
\hline $\mathrm{ICP}+\mathrm{MS}$ & 2 & 170 & 16.7 & 187 & 1 & 0 & 0 & 187 \\
\hline Total & & & & & & $\mathbf{0}$ & 322 & 1272 \\
\hline
\end{tabular}


Table 5. Comparison between manual and automated testing..

\begin{tabular}{|c|c|c|c|c|c|c|c|}
\hline & 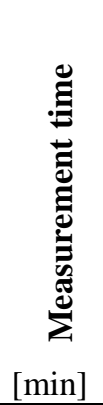 & 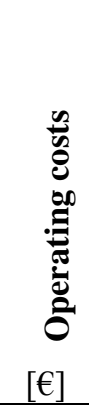 & 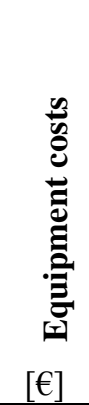 & 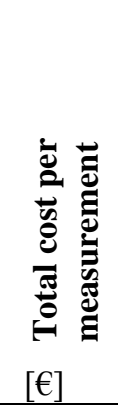 & 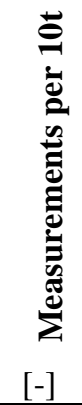 & 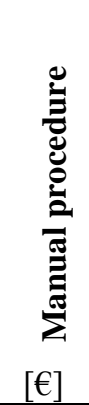 & 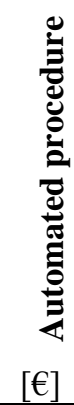 \\
\hline FTIR & 2 & 1.7 & 0.13 & 1.8 & 100 & 179 & \\
\hline Automated FTIR & 0.3 & 0.13 & 0.03 & 0.2 & 100 & & 15 \\
\hline XRF & 2 & 1.7 & 0.17 & 1.8 & 50 & 92 & \\
\hline Automated XRF & 0.3 & 0.25 & 0.06 & 0.3 & 50 & & 15 \\
\hline MCA & 45 & 50.0 & 0.37 & 50.4 & 1 & 50 & \\
\hline $\mathrm{CV}$ & $<0.1$ & 0.13 & 0.02 & 0.1 & 100 & & 14 \\
\hline Total & & & & & & 322 & 45 \\
\hline
\end{tabular}




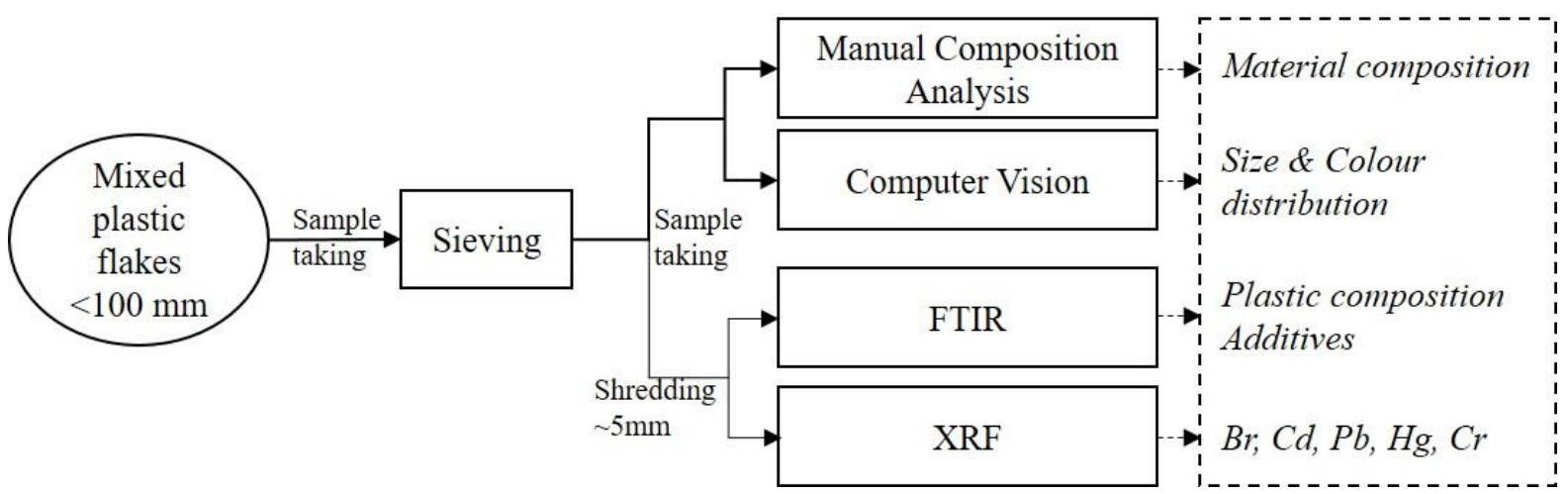

Fig 1. Testing procedure for mixed plastic flakes from WEEE. 


\begin{tabular}{|l|l|}
\hline Composition & \multicolumn{1}{|c|}{ Wecycling Process } \\
\hline Properties
\end{tabular}

Fig 2. Scheme of quality influences of recycled plastics. 


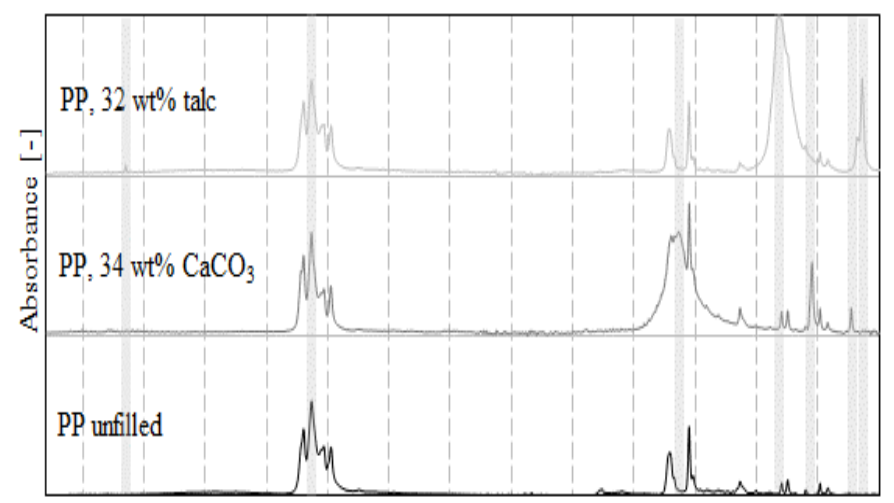

385036003350310028502600235021001850160013501100850600 Wavenumber $\left[\mathrm{cm}^{-1}\right]$

Fig 3. FTIR spectra of pure, $\mathrm{CaCO}_{3}$ and talc filled PP. 


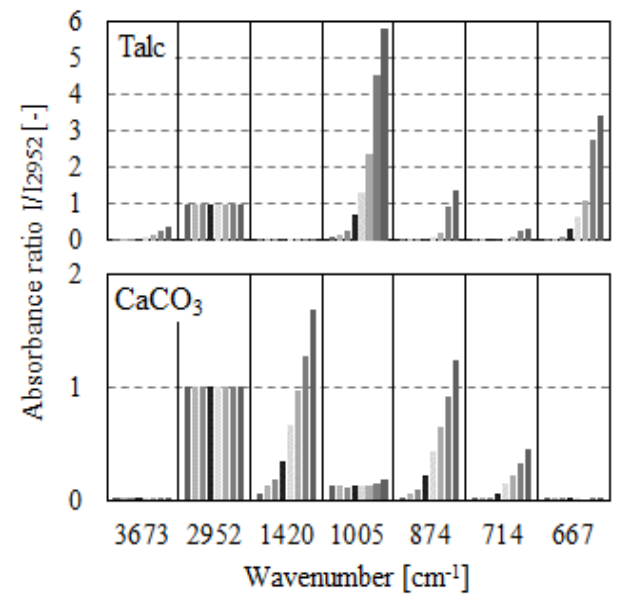

Fig 4. FTIR absorbance ratios for selected peaks for increasing filler concentrations. 


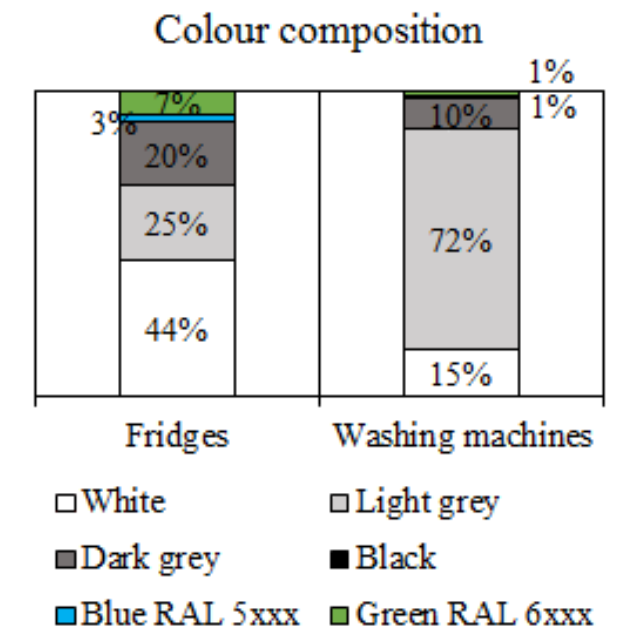

Fig 5. Colour composition of mixed plastic flakes from fridges and washing machines. 


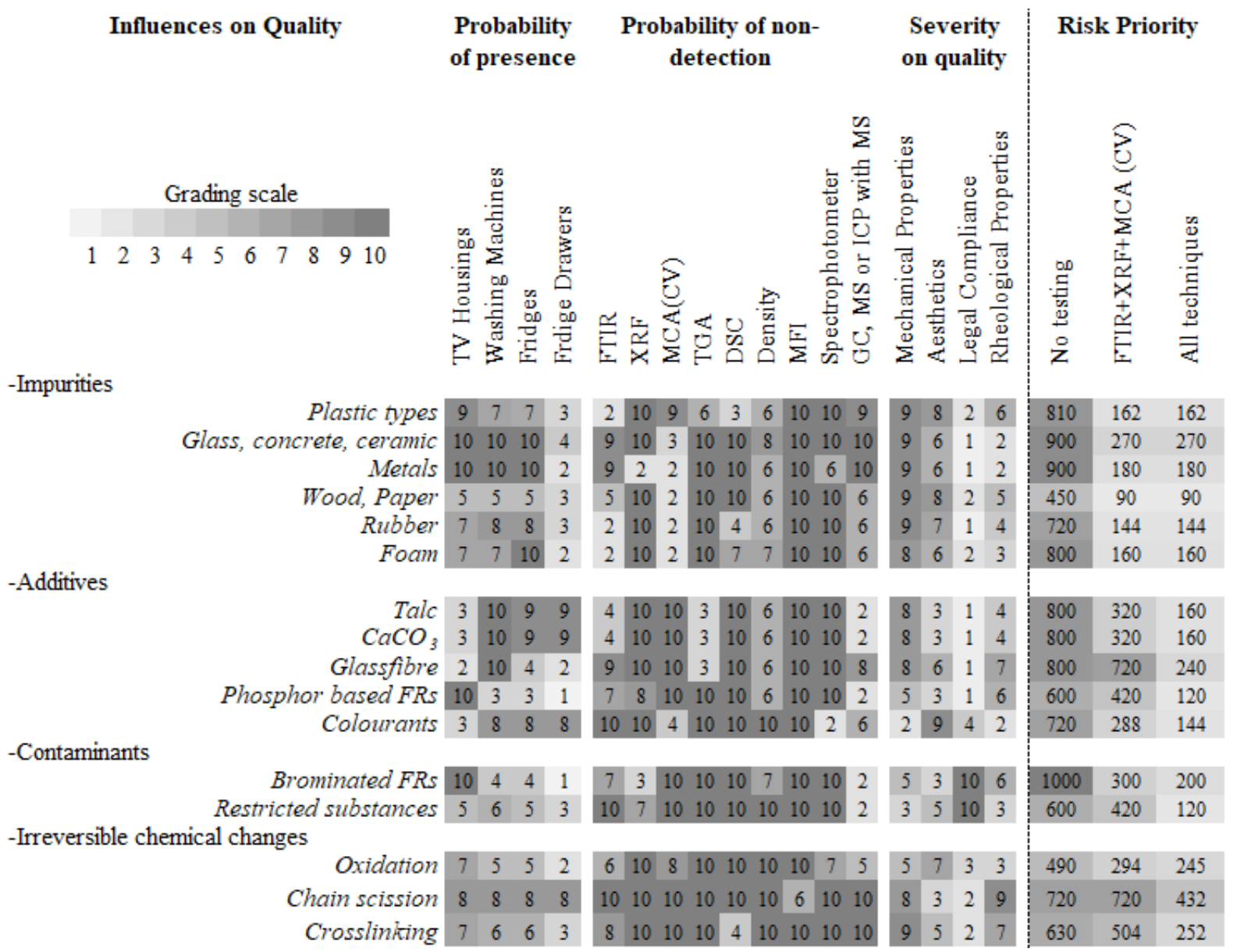

Fig 6. FMEA of the quality assessment of mixed plastic flakes from WEEE. 


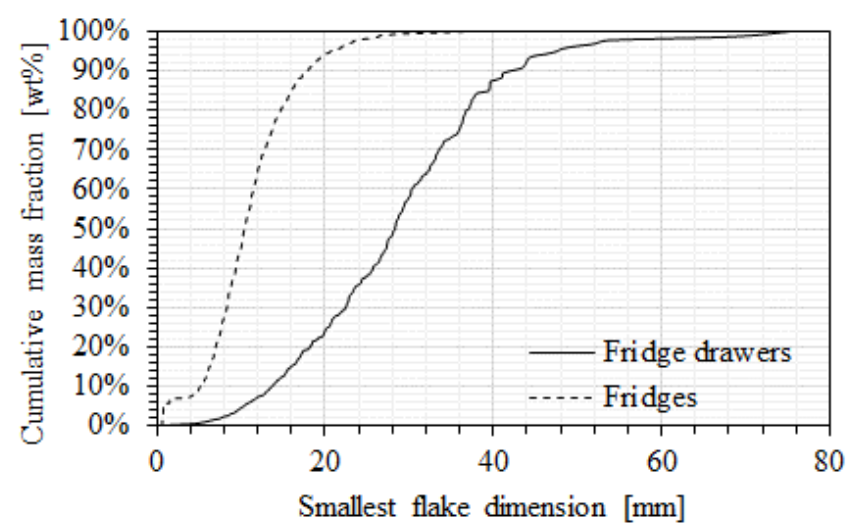

Fig 7. Size distribution of plastic flakes from fridges and white fridge drawers by computer vision. 